\title{
PENGARUH MOTIVASI PELAYANAN PUBLIK, PERCEIVED ORGANIZATIONAL SUPPORT DAN ORGANIZATIONAL CITIZENSHIP BEHAVIOR TERHADAP KINERJA ORGANISASI SEKTOR PUBLIK DI KOTA TANGERANG
}

\author{
Andi Kusuma Negara' ${ }^{1}$, Riska Wahyu Febrianti² \\ Universitas Muhammadiyah Tangerang \\ andikasumanegara75@umt.ac.id ${ }^{1}$, riskawahyu@umt.ac.id²
}

\begin{abstract}
The efforts made by the Tangerang City Government to improve accountability and transparency in the administration of government have been quite successful. This study aims to analyze the factors of public service motivation, perceived organizational support and organizational citizenship behavior that affect the performance improvement of public organizations in the city of Tangerang. The tendency of public service motivation, perceived organizational support and organizational citizenship behavior is thought to be able to drive organizational performance improvement. In order to analyze these factors, a research model developed from the literature review was developed. This model has three hypotheses with four variables: public service motivation, perceived organizational support and organizational citizenship behavior and organizational performance. Data analysis of 115 individuals who have permanent employee status in public institutions in Tangerang City was conducted using Structural Equation Modeling (SEM) as an analysis tool using the LISREL 8.8 program. In the end, this research is also expected to be able to connect the results of the research with the theoretical and policy management implications of Tangerang City Government.
\end{abstract}

Keywords: Public Service Motivation, Perceived Organizational Support, Organizational Citizenship Behavior, Organizational Performance

\begin{abstract}
Abstrak
Usaha yang dilakukan Pemerintah Kota Tangerang membenahi akuntanbilitas dan transparansi penyelenggaraan pemerintahan cukup berhasil. Penelitian ini bertujuan menganalisis faktor-faktor motivasi pelayanan publik, perceived organizational support dan organizational citizenship behavior yang berpengaruh terhadap peningkatan kinerja organisasi publik di Kota Tangerang. Kecenderungan motivasi pelayanan publik, perceived organizational support dan organizational citizenship behavior diduga dapat mendorong peningkatan kinerja organisasi. Dalam rangka menganalisis faktor-faktor tersebut, maka dikembangkanlah model penelitian yang dibentuk dari telaah pustaka. Model ini memiliki tiga hipotesis dengan empat variabel: motivasi pelayanan publik, perceived organizational support dan organizational citizenship behavior dan kinerja organisasi. Analisis data terhadap 115 individu yang telah berstatus pegawai tetap pada institusi publik.di Kota Tangerang dilakukan dengan menggunakan Structural Equation Modeling (SEM) sebagai alat analisis menggunakan program LISREL 8.8. Pada akhirnya, penelitian ini juga diharapkan dapat menghubungkan hasil penelitian dengan implikasi teoritis dan implikasi kebijakan manajemen Pemerintah Kota Tangerang.

Kata Kunci : Motivasi Pelayanan Publik, Perceived Organizational Support, Organizational Citizenship Behavior, Kinerja Organisasi
\end{abstract}




\section{PENDAHULUAN \\ Latar Belakang}

Organisasi sektor publik adalah bagian dari sistem ekonomi negara yang bertujuan untuk mewujudkan kesejahteraan publik. Institusi pemerintah, partai politik, sekolah, rumah sakit adalah organisasi sektor publik (Nordiawan, 2009). Layanan kepada masyarakat adalah fokus utama organisasi sektor publik.

Birokrasi pelayanan publik di Indonesia masih lekat dengan stigma negatif yang terkesan lamban, inefisien, inefektif serta identik dengan penyakit yang merugikan kepentingan masyarakat. Citra yang berkembang di masyarakat adalah birokrasi pemerintah masih kaku dan tidak responsif terhadap kebutuhan warga pengguna layanan (Dwianto, 2012).

Kota Tangerang adalah salah satu kota dengan tingkat kebutuhan masyarakat akan pelayanan publik yang tinggi dan membutuhkan peran pemerintah agar dapat mengakomodasi setiap bentuk kebutuhan tersebut. Salah satu upaya yang dilakukan oleh Pemerintah Kota Tangerang ialah meningkatkan akuntabilitas kinerjanya. Usaha yang dilakukan Pemerintah Kota Tangerang membenahi akuntanbilitas dan transparansi penyelenggaraan pemerintahan cukup berhasil. Dimulai dari peningkatan pelayanan publik dengan terus berupaya mempermudah akses pelayanan publik ke masyarakat melalui pemanfaatan teknologi informasi.

Untuk meningkatkan kinerja organisasi yang dapat menciptakan pelayanan publik berkualitas bagi masyarakat adalah motivasi pelayanan publik. Motivasi pelayanan publik mengandung makna sebagai motivasi yang mendorong seseorang pekerja atau pegawai untuk memberikan pelayanan yang terbaik kepada publik (Perry et.al, 1990).

Menurut Eisenberger et al. (1986), Perceived Organizational Support (POS) akan dipengaruhi oleh berbagai aspek cara perlakuan organisasi untuk karyawannya yang akan mempengaruhi interpretasi karyawan akan motif organisasi yang mendasari perlakuan tersebut, hal ini menandakan bahwa karyawan berharap mendapat dukungan organisasi dalam berbagai macam situasi. Dukungan yang terpenting adalah membuat para karyawan merasa puas terhadap timbal balik dari organisasi dan merasakan bahwa organisasi peduli terhadap kesejahteraan karyawan, sehingga dapat bekerja dengan semangat serta dapat meningkatkan kinerja organisasi.

Kinerja yang berkualitas dan maksimal adalah tuntutan organisasi yang dapat ditunjukkan melalui Organizational Citizenship Behavior (OCB). Organ et.al. (2006) berpendapat bahwa OCB memberikan kontribusi bagi kesuksesan organisasi dan memberikan keunggulan dalam bersaing. OCB memberikan dampak positif pada organisasi, karena membuat karyawan memiliki kualitas organisasi yang tinggi, membantu keefektifan organisasi, dan dapat membentuk lingkungan kerja yang baik sehingga memunculkan dedikasi karyawan.

\section{Rumusan Masalah}

Sesuai dengan latar belakang yang dikemukakan, maka rumusan masalah yang dibangun sebagai berikut: 1)Bagaimana pengaruh motivasi pelayanan publik terhadap kinerja organisasi?. 2) Bagaimana pengaruh perceived organizational support terhadap kinerja organisasi?. 3 )Bagaimana pengaruh organizational citizenship behavior terhadap kinerja organisasi?

\section{Tujuan Penelitian}

Berdasarkan rumusan masalah yang dibangun, maka tujuan penelitian ini untuk menganalisis:

1) Pengaruh motivasi pelayanan publik terhadap kinerja organisasi. 2) Pengaruh perceived organizational support terhadap kinerja organisasi. 3) Pengaruh organizational citizenship behavior terhadap kinerja organisasi. 


\section{TINJAUAN PUSTAKA}

\section{Organisasi Sektor Publik}

Sulistyani (2009) memandang organisasi publik sebagai instansi pemerintah yang memiliki legalitas formal, difasilitasi oleh negara untuk menyelenggarakan kepentingan rakyat di segala bidang yang sifatnya kompleks. Selain itu, Mahmudi (2011) memandang organisasi publik sebagai instansi yang memiliki tujuan untuk memberikan pelayanan kepada masyarakat dan mewujudkan kesejahteraan sosial.

Sedikit berbeda dengan definisi organisasi publik di atas, Mahsun (2012) menjelaskan bahwa "Organisasi publik bukan hanya organisasi sosial, organisasi non profit dan organisasi pemerintah. Organisasi sektor publik adalah organisasi yang berhubungan dengan kepentingan umum dan penyediaan barang atau jasa kepada publik yang dibayar melalui pajak atau pendapatan negara lain yang diatur dengan hukum".

\section{Kinerja Organisasi}

Kinerja (performance) adalah gambaran mengenai tingkat pencapaian pelaksanaan suatu kegiatan/program kebijakan dalam mewujudkan sasaran, tujuan, misi dan visi organisasi yang tertuang dalam strategic planning suatu organisasi (Mahsun, 2012).

Sedangkan menurut Wibowo dalam Pasolong (2010), kinerja organisasi merupakan efektifitas organisasi secara menyeluruh untuk kebutuhan yang ditetapkan dari setiap kelompok yang berkenaan melalui usaha-usaha yang sistematik dan meningkatkan kemampuan organisasi secara terus menerus untuk mencapai kebutuhannya secera efektif.

Menurut Sinambela (2012), kinerja organisasi merupakan kumulatif kinerja pegawai, oleh karenanya semakin tinggi kinerja pegawai akan semakin tinggi pula kinerja organisasi. Sedangkan menurut Nasucha dalam (Sinambela,2012:186), kinerja organisasi didefinisikan juga sebagai efektivitas organisasi secara menyeluruh untuk memenuhi kebutuhan yang ditetapkan dari setiap kelompok yang berkenaan melalui usaha-usaha yang sistemik dan meningkatkan kemampuan organisasi secara terus menerus untuk mencapai kebutuhannya secara efektif.

\section{Motivasi Pelayanan Publik}

Perry dan Wise (1990) mendefinisikan Public Service Motivation (PSM) sebagai kecenderungan individual untuk merespon motif dasar yang unik yang terdapat dalam institusi dan organisasi publik. Hal ini didasarkan pada pendapat bahwa terdapat orangorang yang tertarik dan termotivasi untuk bekerja di sektor publik. Tiga motif yang dicirikan dalam Public Service Motivation (PSM) yaitu, pertama motif rasional yang didasarkan pada individual utility maximization dimana indvidu tertarik untuk bekerja di sektor publik karena memiliki 22 kepentingan untuk mendukung sektor privat tertentu pada saat ia memiliki kewenangan dalam perumusan kebijakan publik. Kedua, motif normatif yang didasarkan pada satu keinginan untuk melayani kepentingan publik, loyalitas terhadap tugas dan pemerintah. Ketiga, motif afektif yang didasarkan pada faktor emosional atau komitmen terhadap sebuah program yang didasarkan atas keyakinan mengenai manfaat sosialnya dan rasa patriotisme.

Public Service Motivation (PSM) yang pada umumnya terdapat di kalangan para pegawai di sektor publik berkenaan dengan empat dimensi, yaitu :

1. Ketertarikan untuk membuat kebijakan publik (attraction to public policy making), dimensi ini berkaitan dengan motivasi untuk mencapai prestasi yang memungkinkan individu untuk mencapai kepuasan batin atau pribadi.

2. Tanggung jawab terhadap kepentingan publik dan kewajiban sebagai warga negara (commitment to public interest and civic duty), dimensi ini berkaitan dengan keinginan untuk melayani publik yang didorong oleh keyakinan yang tulus dan kasih sayang terhadap kepentingan sosial. 
3. Simpati (compassion), dimensi ini dicirikan oleh adanya keinginan untuk menolong orang lain, sifat mementingkan kepentingan orang lain, sikap ikut merasakan perasaan orang lain, dan keinginan sosial lainnya.

4. Sikap pengorbanan diri (self-sacrifice), dimensi ini berkaitan dengan sikap kecintaan terhadap tanah air, tanggung jawab kepada tugas, dan kesetiaan kepada negara, kesadaran yang tinggi untuk membagikan dan berkorban demi untuk kelangsungan hidup organisasi.

\section{Pengembangan Hipotesis}

\section{Motivasi Pelayaan Publik dan Kinerja Organisasi}

Motivasi pelayanan publik sangat berpengaruh terhadap kinerja pegawai dalam mengabdikan dirinya kepada masyarakat karena salah satu bentuk atau bagian khas dari motivasi pelayanan publik adalah untuk mendorong seorang pekerja (pegawai) untuk mementingkan kepentingan organisasi, dan menyumbangkan darma baktinya kepada kesejahteraan organisasi dan masyarakat. Dalam salah satu kajian Perry et.al (2008) dijelaskan pula bahwa motvasi pelayanan publik itu dipengaruhi oleh berbagai latar belakang dari seseorang individu yang berkenaan dengan lima perkara, dan salah satu yang berkaitan dengan pengaruh motivasi pelayanan publik adalah yang ke tiga yaitu Profesionalisme (Professional Identification).

Hipotesis 1 : Semakin tinggi motivasi pelayanan publik, maka akan semakin tinggi kinerja organisasi..

\section{Perceived organizational support dan Kinerja Organisasi}

Eisenberger et al.,(1986) menjelaskan bahwa Perceived Organizational Support (POS) akan dipengaruhi oleh berbagai aspek cara perlakuan organisasi untuk karyawannya dan pada gilirannya, akan mempengaruhi interpretasi karyawan akan motif organisasi yang mendasari perlakuan tersebut, hal ini menandakan bahwa karyawan berharap mendapat dukungan organisasi dalam berbagai macam situasi. Karyawan menganggap organisasi yang memberikan dukungan yang paling berarti berupa perhatian yang diberikan oleh pimpinan yaitu memberi tahu jika ada pekerjaan yang kurang baik yang dilakukan oleh para karyawan sehingga para karyawan dapat mengetahui dan memperbaiki kinerja yang kurang baik.

Hipotesis 2 : Semakin tinggi perceived organizational support, maka akan semakin tinggi kinerja organisasi.

\section{Organizational Citizenship Behavior dan Kinerja Organisasi}

Organizational Citizenship Behavior (OCB) sangat penting artinya untuk menunjang keefektifan fungsi-fungsi organisasi, terutama dalam jangka panjang. Menurut Padsakoff (2000), organizational citizenship behavior mempengaruhi keefektifan organisasi. Organizational citizenship behaviour memberikan peluang bagi setiap personil institusi publik untuk bahu-membahu, diskusi dan saling melengkapi dalam bekerja, akibatnya setiap personil institusi publik menjadi kompak, dan memberikan kontribusi pada pencapaian peningkatan kinerja (Komalasari, 2013).

Hipotesis 3 : Semakin tinggi organizational citizenship behavior, maka akan semakin tinggi kinerja organisasi.

\section{METODE PENELITIAN}

\section{Jenis dan Sumber Data}

Pada penelitian ini jenis data yang digunakan adalah data primer yaitu data yang dicari, diperoleh, diolah serta belum pernah dipublikasikan kepada berbagai pihak yang berkepentingan. Proses pencarian data primer dilakukan dengan cara menyebarkan kuesioner kepada individu yang memiliki karakteristik sesuai dengan kriteria sampel yang diajukan. 
Dalam penelitian ini yang menjadi data primer adalah data yang berkaitan dengan motivasi pelayanan, Perceived Organizational Support, Organizational Citizenship Behavior dan kinerja organisasi. Untuk memperoleh data tersebut, peneliti menyebarkan kuesioner kepada individu yang telah berstatus pegawai tetap pada institusi publik di Kota Tangerang.

Pernyataan-pernyataan dalam kuesioner dibuat dengan menggunakan skala 1-10 (skala genap) untuk mendapatkan data yang bersifat interval dan diberi skor atau nilai. Hal ini untuk menghindari jawaban responden yang cenderung memilih jawaban di tengah, sehingga akan menghasilkan respon yang mengumpul di tengah.

\section{Sampel Penelitian}

Populasi dalam penelitian ini adalah individu yang telah berstatus pegawai tetap pada institusi publik.di Kota Tangerang.

Teknik pengambilan sampel dalam penelitian ini menggunakan metode convenience sampling yaitu pengumpulan informasi dari anggota populasi dengan senang hati bersedia memberikannya (Sekaran, 2007). Alasan menggunakan metode ini adalah karena keterbatasan jumlah pegawai yang dapat ditemui untuk dijadikan responden karena kesibukan para pegawai tersebut.

Bentler dan Chou (1987) dalam Wijanto (2008) menyarankan bahwa rasio sampel paling rendah per variabel teramati yaitu 5 responden, sehingga dapat mencukupi untuk distribusi normal saat sebuah variabel laten memiliki beberapa variabel teramati (indikator). Berdasarkan hal tersebut, maka ukuran sampel penelitian ini dengan menggunakan estimasi maximum likelihood yaitu sebanyak 115 responden $(5 \times 23$ variabel teramati).

\section{Operasionalisasi Variabel}

Variabel-variabel yang akan diukur dalam penelitian ini yaitu:

1. Variabel bebas atau independen

Variabel independen pada penelitian ini adalah motivasi pelayanan publik, perceived organizational support dan organizational citizenship behavior.

2. Variabel terikat atau dependen

Variabel dependen dalam hal ini adalah kinerja organisasi.

\section{Metode Analisis Data}

Karena dalam penelitian ini menggunakan indikator untuk mengukur setiap konstruknya, dan juga model pengukuran bersifat struktural, maka pendekatan dalam permodelan yang digunakan dalam penelitian ini adalah Structural Equation Modelling (SEM) dengan bantuan perangkat lunak LISREL 8.8.

Langkah-langkah analisis dengan metode Structural Equation Modelling (SEM) secara ringkas diuraikan sebagai berikut:

1. Merancang persamaan struktural

2. Perancangan ini didasarkan pada rumusan masalah atau hipotesis penelitian untuk menyatakan hubungan kausalitas antara berbagai konstruk.

3. Merancang model pengukuran

4. Perancangan model ini digunakan untuk mengetahui validitas dan reliabilitas yang menghubungkan indikator dengan variabel latennya.

5. Konstruksi Diagram Jalur Penelitian.

6. Konversi Diagram Jalur ke Sistem Persamaan

7. Evaluasi Kriteria Goodness of Fit

Uji kesesuaian model dilakukan dengan menggunakan beberapa ukuran kesesuaian model.

\section{Pengujian Hipotesis}

Rancangan uji hipotesis dalam penelitian ini disajikan berdasarkan tujuan penelitian. Tingkat kepercayaan yang digunakan adalah 95\%, sehingga tingkat signifikansi sebesar $(\alpha)=$ $5 \%=0,05$. Dan menghasilkan nilai t-tabel sebesar 1,96 sehingga: 
- Jika nilai t-hitung lebih kecil dari nilai t-tabel (t-hitung $<1,96$ ), maka H0 diterima dan Ha ditolak.

- Jika nilai t-hitung lebih besar dari nilai t-tabel (t-hitung > 1,96), maka H0 ditolak dan Ha diterima.

\section{HASIL PENELITIAN DAN PEMBAHASAN}

\section{Hasil Penelitian}

\section{Evaluasi Model Pengukuran (Uji Validitas dan Reliabilitas)}

Dalam penelitian ini, langkah pertama yang dilakukan adalah mengevaluasi hubungan antara variabel dengan indikatornya. Evaluasi ini meliputi indikator validitas, reliabilitas konstruk, dan nilai average variance extracted (AVE). Indikator validitas dapat dilihat dari nilai loading factor. Bila nilai loading factor suatu indikator lebih dari 0,70; maka dapat dikatakan valid. Sebaliknya, bila nilai loading factor kurang dari 0,70; maka harus dikeluarkan dari model

Berikut adalah evaluasi model pengukuran terhadap indikator motivasi pelayanan publik (MPP), perception organizational support (POS), organizational citizenship behavior (OCB), dan kinerja organisasi (KO).

\section{Gambar 4.1}

Basic Model (Standardized Solutions)

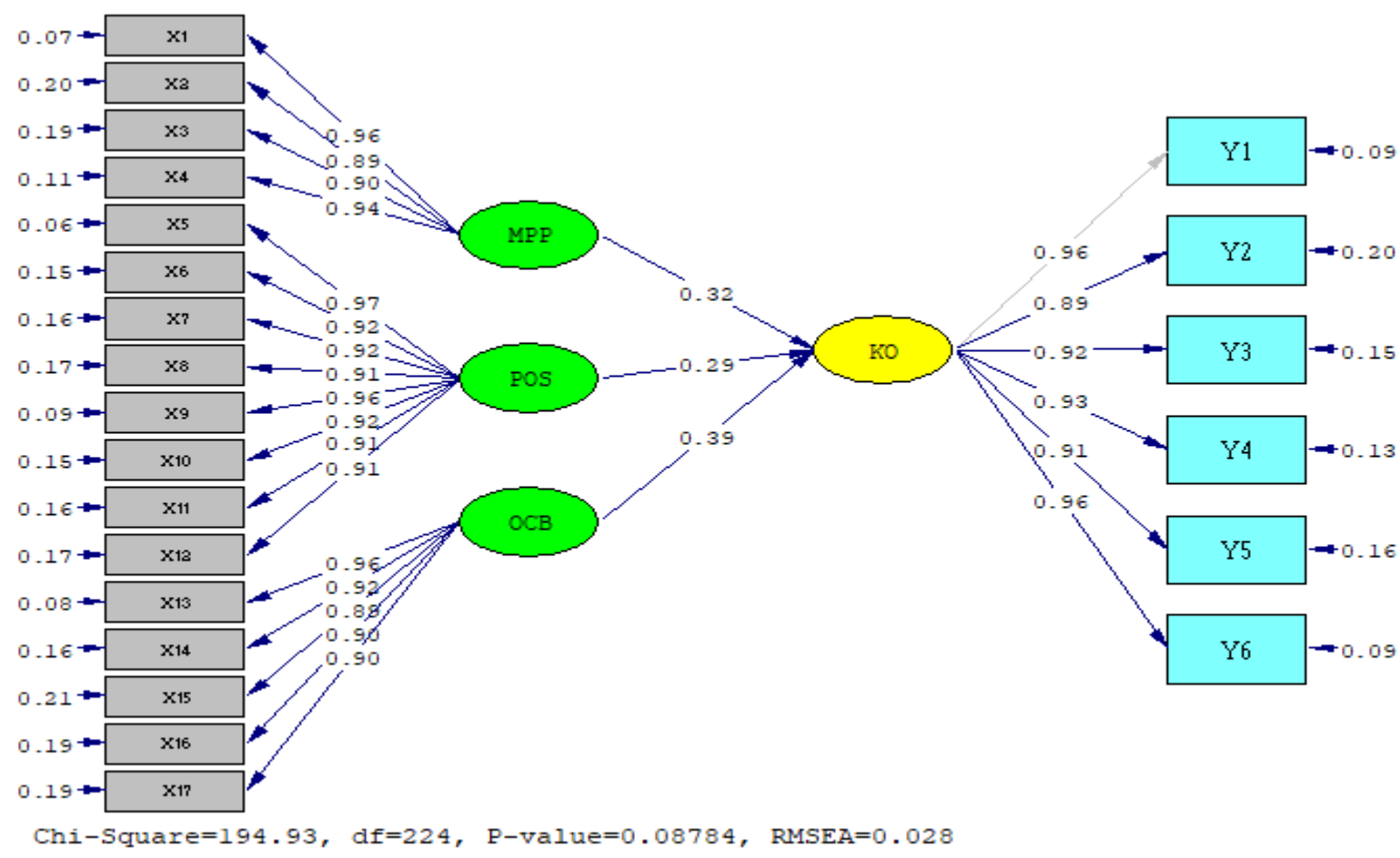

Sumber : Hasil Olah Data Lisrel

Tabel 4.1

Nilai Loading Factor Indikator

\begin{tabular}{|l|c|}
\hline \multicolumn{1}{|c|}{ Indikator } & Loading Factor \\
\hline X1 <- Motivasi Pelayanan Publik (MPP) & 0,96 \\
\hline X2 <- Motivasi Pelayanan Publik (MPP) & 0,89 \\
\hline X3 <- Motivasi Pelayanan Publik (MPP) & 0,90 \\
\hline X4 <- Motivasi Pelayanan Publik (MPP) & 0,94 \\
\hline X5 <- Perception Organizational Support (POS) & 0,97 \\
\hline X6 <- Perception Organizational Support (POS) & 0,92 \\
\hline X7 <- Perception Organizational Support (POS) & 0,92 \\
\hline X8 <- Perception Organizational Support (POS) & 0,91 \\
\hline
\end{tabular}




\begin{tabular}{|c|c|}
\hline X9 <- Perception Organizational Support (POS) & 0,96 \\
\hline $\mathrm{X} 10<-$ Perception Organizational Support (POS) & 0,92 \\
\hline $\mathrm{X} 11<-$ Perception Organizational Support (POS) & 0,91 \\
\hline $\mathrm{X} 12<-$ Perception Organizational Support (POS) & 0,91 \\
\hline X13 <- Organizational Citizenship Behavior (OCB) & 0,96 \\
\hline X14 <- Organizational Citizenship Behavior (OCB) & 0,92 \\
\hline X15 <- Organizational Citizenship Behavior (OCB) & 0,89 \\
\hline X16 <- Organizational Citizenship Behavior (OCB) & 0,90 \\
\hline X17 <- Organizational Citizenship Behavior (OCB) & 0,90 \\
\hline Y1 <- Kinerja Organisasi (KO) & 0,96 \\
\hline Y2 <- Kinerja Organisasi (KO) & 0,89 \\
\hline Y3 <- Kinerja Organisasi (KO) & 0,92 \\
\hline Y4 <- Kinerja Organisasi (KO) & 0,93 \\
\hline Y5 <- Kinerja Organisasi (KO) & 0,91 \\
\hline Y6 <- Kinerja Organisasi (KO) & 0,96 \\
\hline
\end{tabular}

Sumber: Data primer diolah (2019)

Berdasarkan Gambar 4.1 dan Tabel 4.1, setiap indikator yang membentuk konstruk memiliki loading factor > 0,70; maka dapat dinyatakan bahwa semua indikator valid.

Evaluasi selanjutnya adalah pemeriksaan reliabilitas konstruk yang menggunakan dua ukuran (Hair dkk., 2006), yaitu:

1. Construct Realibility Measure (CR), dengan persyaratan nilai CR $\geq 0,70$.

2. Average Variance Extracted Measure (AVE), dengan persyaratan nilai AVE $\geq 0,50$.

Berdasarkan hasil perhitungan didapatkan nilai Construct Realibility (CR) dan nilai Average Variance Extracted (AVE) seperti ditunjukkan pada Tabel 4.3.

Tabel 4.2

Nilai Construct Realibility (CR) dan Average Variance Extracted (AVE)

\begin{tabular}{|l|c|c|}
\hline \multicolumn{1}{|c|}{ Konstruk } & $\begin{array}{c}\text { Construct } \\
\text { Realibility (CR) }\end{array}$ & $\begin{array}{c}\text { Average Variance } \\
\text { Extracted (AVE) }\end{array}$ \\
\hline Motivasi Pelayanan Publik (MPP) & 0,98 & 0,92 \\
\hline Perception Organizational Support (POS) & 0,99 & 0,92 \\
\hline Organizational Citizenship Behavior (OCB) & 0,98 & 0,91 \\
\hline Kinerja Organisasi (KO) & 0,99 & 0,92 \\
\hline
\end{tabular}

Sumber: Data primer diolah (2019)

Berdasarkan Tabel 4.2, semua nilai construct reliability $(\mathrm{CR}) \geq 0,70$; berarti reliabilitas konstruk terpenuhi, dan juga semua nilai average variance extracted (AVE) $\geq 0,50$; berarti ukuran kelayakan terpenuhi.

2. Evaluasi Goodness of Fit (GOF)

Tujuan evaluasi GOF adalah menguji kesesuaian model dengan data statistik. Berikut ringkasan ukuran kesesuaian model seperti yang ditunjukkan pada Tabel 4.3.

Tabel 4.3

Ringkasan Ukuran Kesesuaian Model

\begin{tabular}{|c|c|c|c|}
\hline $\begin{array}{c}\text { Indikator } \\
\text { GoF }\end{array}$ & $\begin{array}{c}\text { Ukuran yang } \\
\text { Diharapkan }\end{array}$ & $\begin{array}{c}\text { Hasil } \\
\text { Estimasi }\end{array}$ & Kesimpulan \\
\hline Ch-square & $\begin{array}{c}\mathrm{df}=224, \alpha=5 \% \\
<259,914\end{array}$ & 194,93 & Good Fit \\
\hline Significancy Probability & $\geq 0,05$ & 0,09 & Good Fit \\
\hline RMSEA & $<0,08$ & 0,03 & Good Fit \\
\hline GFI & $\geq 0,90$ & 0,91 & Good Fit \\
\hline AGFI & $\geq 0,90$ & 0,91 & Good Fit \\
\hline CMIN/DF & $<2,00$ & 0,87 & Good Fit \\
\hline TLI & $\geq 0,95$ & 0,93 & Good Fit \\
\hline CFI & $\geq 0,95$ & 0,93 & Good Fit \\
\hline
\end{tabular}


Sumber: Data primer diolah (2019)

Berdasarkan Tabel 4.3, semua ukuran memiliki indeks kesesuaian model yang baik ( good fit), dengan demikian maka dapat dilanjutkan pada analisis berikutnya.

\section{Evaluasi Model Struktural}

Langkah pertama untuk mengevaluasi model struktural adalah melihat covariance matrix dari variabel laten yang menunjukkan nilai korelasi antara konstruk seperti pada Tabel 4.4.

Tabel 4.4

Nilai Korelasi Antar Konstruk

\begin{tabular}{|c|c|c|c|c|}
\hline & MPP & POS & OCB & KO \\
\hline MPP & 1,00 & & & \\
\hline POS & 0,69 & 1,00 & & \\
\hline OCB & 0,69 & 0,52 & 1,00 & \\
\hline KO & 0,74 & 0,57 & 0,60 & 1,00 \\
\hline
\end{tabular}

Sumber: Data primer diolah (2019)

Keterangan:

MPP = Motivasi Pelayanan Publik

POS $=$ Perception Organizational Support

$\mathrm{OCB}=$ Organizational Citizenship Behavior

$\mathrm{KO}=$ Kinerja Organisasi

Kemudian untuk melihat signifikansi hubungan jalur antar konstruk maka dilihat t-hitung jalur seperti pada gambar 4.3 dan Tabel 4.5.

Gambar 4.2

Structural Model (T-Values)

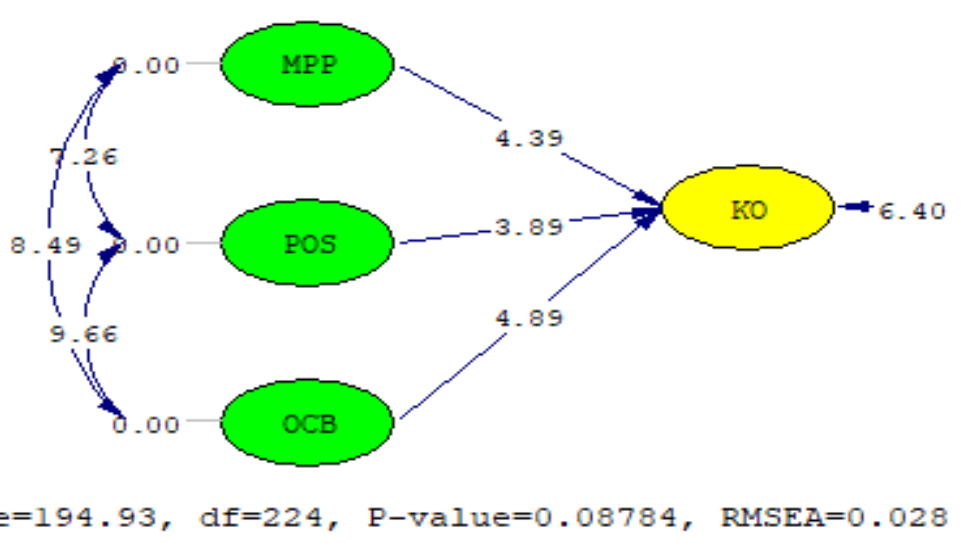

Tabel 4.5

Nilai t-hitung Jalur Antar Konstruk

\begin{tabular}{|c|c|}
\hline Jalur & t-hitung \\
\hline MPP $\rightarrow$ KO & 4,39 \\
\hline POS $\rightarrow$ KO & 3,89 \\
\hline OCB $\rightarrow$ KO & 4,89 \\
\hline
\end{tabular}

Sumber: Data primer diolah (2019)

Keterangan:

MPP = Motivasi Pelayanan Publik

POS = Perception Organizational Support

$\mathrm{OCB}=$ Organizational Citizenship Behavior

$\mathrm{KO}=$ Kinerja Organisasi 
Berdasarkan Gambar 4.2 dan Tabel 4.5 semua nilai t-hitung jalur > 1,96.; maka semua hubungan jalur antara konstruk bersifat signifikan.

Sedangkan nilai koefisien jalur antara konstruk dapat dilihat pada Gambar 4.3 dan Tabel 4.6 berikut ini.

\section{Gambar 4.2}

Structural Model (Standardized Solutions)

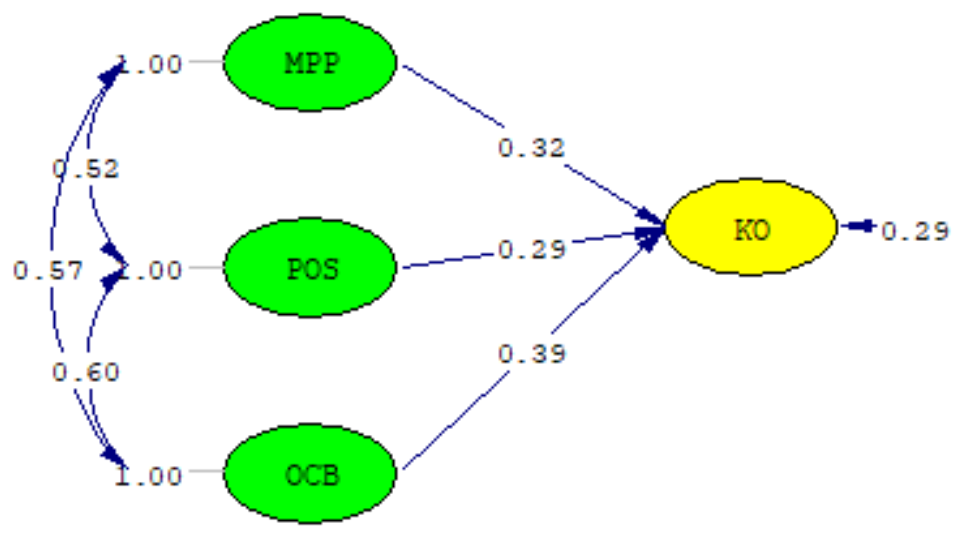

Chi-Square=194.93, df=224, P-value=0.08784, RMSEA=0.028

Tabel 4.6

Koefisien Jalur Antara Konstruk

\begin{tabular}{|c|c|}
\hline Jalur & Koefisen \\
\hline MPP $\rightarrow$ KO & 0,32 \\
\hline POS $\rightarrow$ KO & 0,29 \\
\hline OCB $\rightarrow$ KO & 0,39 \\
\hline
\end{tabular}

Sumber: Data primer diolah (2019)

Keterangan:

MPP = Motivasi Pelayanan Publik

POS $=$ Perception Organizational Support

$\mathrm{OCB}=$ Organizational Citizenship Behavior

$\mathrm{KO}=$ Kinerja Organisasi

Untuk mendapatkan persentase pengaruh antara konstruk maka koefisien jalur dikalikan nlai korelasi antara konstruk kemudian dikalikan $100 \%$ seperti pada Tabel 4.7 .

Tabel 4.7

Persentase Pengaruh Antara Konstruk

\begin{tabular}{|l|c|c|c|}
\hline \multicolumn{1}{|c|}{ Jalur } & Koefisien & $\begin{array}{c}\text { Nilai } \\
\text { Korelasi }\end{array}$ & $\begin{array}{c}\text { Persentase } \\
\text { Pengaruh }\end{array}$ \\
\hline MPP -> KO & 0,32 & 0,74 & $23,68 \%$ \\
\hline POS -> KO & 0,29 & 0,57 & $16,53 \%$ \\
\hline OCB -> KO & 0,39 & 0,60 & $23,40 \%$ \\
\hline
\end{tabular}

Sumber: Data primer diolah (2019)

Keterangan:

MPP = Motivasi Pelayanan Publik

$\mathrm{POS}=$ Perception Organizational Support

$\mathrm{OCB}=$ Organizational Citizenship Behavior

$\mathrm{KO}=$ Kinerja Organisasi

\section{Pembahasan}




\section{Pengaruh Motivasi Pelayanan Publik terhadap Kinerja organisasi}

Nilai t-hitung hubungan jalur antara motivasi pelayanan publik terhadap kinerja organisasi sebesar 4,39>1,96; maka H1 diterima, artinya motivasi pelayanan publik mempunyai pengaruh signifikan terhadap kinerja organisasi.

Berdasarkan hasil penelitian, motivasi pelayanan publik berpengaruh terhadap kinerja organisasi dengan nilai korelasi sebesar 0,74 yang berarti motivasi pelayanan publik memberikan pengaruh kuat berarah positif terhadap kinerja organisasi.

Persentase pengaruh motivasi pelayanan publik berpengaruh terhadap kinerja organisasi sebesar 23,68\%; berarti motivasi pelayanan publik berkontribusi sebesar $23,68 \%$ terhadap kinerja organisasi.

Arah hubungan positif motivasi pelayanan publik dengan kinerja organisasi menunjukkan bahwa semakin tinggi motivasi pelayanan publik maka semakin tinggi kinerja organisasi.

Hasil penelitian yang menunjukkan bahwa motivasi pelayanan publik mempengaruhi kinerja organisasi publik, hasil yang diperoleh sejalan dengan hipotesis yang diajukan, kuatnya motivasi karena adanya kepercayaan masyarakat kepada mereka, adanya penghargaan dan pengakuan tehadap mereka yang bekerja pada organisasi sektor publik meningkatkan motivasi pelayanan publik (Komalasari, 2013).

\section{Pengaruh Perception Organizational Support terhadap Kinerja organisasi}

Nilai t-hitung hubungan jalur antara Perception Organizational Support terhadap kinerja organisasi sebesar 3,89 >1,96; maka H2 diterima, artinya Perception Organizational Support mempunyai pengaruh signifikan terhadap kinerja organisasi.

Berdasarkan hasil penelitian, Perception Organizational Support berpengaruh terhadap kinerja organisasi dengan nilai korelasi sebesar 0,57 yang berarti Perception Organizational Support memberikan pengaruh sedang berarah positif terhadap kinerja organisasi.

Persentase pengaruh perception organizational support berpengaruh terhadap kinerja organisasi sebesar 16,53\%; berarti perception organizational support berkontribusi sebesar $16,53 \%$ terhadap kinerja organisasi.

Arah hubungan positif perception organizational support dengan kinerja organisasi menunjukkan bahwa semakin tinggi perception organizational support maka semakin tinggi kinerja organisasi.

Hasil penelitian mengkonfirmasi pendapat Rhoades dan Eisenberger (2002) yang menunjukkan bahwa jika karyawan menganggap bahwa dukungan organisasi yang diterimanya tinggi, maka karyawan tersebut akan menyatukan keanggotaan sebagai anggota organisasi ke dalam identitas dirinya dan kemudian mengembangkan hubungan dan persepsi yang lebih positif terhadap organisasi. Hal tersebut akan meningkatkan komitmen karyawan untuk membantu organisasi mencapai tujuannya, dan meningkatkan kinerja organisasi.

\section{Pengaruh Organizational Citizenship Behavior terhadap Kinerja organisasi}

Nilai t-hitung hubungan jalur antara organizational citizenship behavior terhadap kinerja organisasi sebesar 4,89>1,96; maka H3 diterima, artinya organizational citizenship behavior mempunyai pengaruh signifikan terhadap kinerja organisasi.

Berdasarkan hasil penelitian, organizational citizenship behavior berpengaruh terhadap kinerja organisasi dengan nilai korelasi sebesar 0,60 yang berarti organizational citizenship behavior memberikan pengaruh kuat berarah positif terhadap kinerja organisasi.

Persentase pengaruh organizational citizenship behavior berpengaruh terhadap kinerja organisasi sebesar 23,40\%; berarti organizational citizenship behavior berkontribusi sebesar $23,40 \%$ terhadap kinerja organisasi. 
Arah hubungan positif organizational citizenship behavior dengan kinerja organisasi menunjukkan bahwa semakin tinggi organizational citizenship behavior maka semakin tinggi kinerja organisasi.

Hasil penelitian menunjukkan bahwa organizational citizenship behaviour memberikan peluang bagi setiap personil institusi publik untuk bahu-membahu, diskusi dan saling melengkapi dalam bekerja, akibatnya setiap personil institusi publik menjadi kompak, dan memberikan kontribusi pada peningkatan kinerja organisasi (Komalasari, 2013).

\section{KESIMPULAN DAN SARAN \\ Simpulan}

berikut:

Berdasar hasil penelitian dan pembahasan, maka dapat diambil kesimpulan sebagai

1. Motivasi pelayanan publik berpengaruh signifikan terhadap kinerja organisasi sektor publik di Kota Tangerang.

2. Perception Organizational Support berpengaruh signifikan terhadap kinerja organisasi sektor publik di Kota Tangerang.

3. Organizational Citizenship Behavior berpengaruh signifikan terhadap kinerja organisasi Saran sektor publik di Kota Tangerang.

Berdasarkan kesimpulan di atas, dapat dikemukakan beberapa saran yang diharapkan dapat bermanfaat. Adapun saran yang diberikan antara lain:

a. Saran Operasional

Pegawai organisasi sektor publik disarankan untuk terus mengembangkan perilaku Organizational Citizenship Behaviour dalam bekerja, karena penerapan perilaku tersebut tentu akan menciptakan kerja sama team yang solid pada dan saling bahu membahu dalam menjalankan tugas dan tanggung jawab, serta sangat diyakini akan berkontribusi bagi peningkatan kinerja organisasi sektor publik khususnya di kota Tangerang. Begitu pula Perception Organizational Support sebagai pendukung untuk meningkatkan kinerja organisasi sektor publik khususnya di kota Tangerang

b. Saran Akademis

Dalam pengembangan ilmu manajemen pemasaran diharapkan hasil penelitian ini dapat dijadikan acuan agar penelitian berikutmya dapat menggunakan variabel yang sama, metode yang sama tetapi dengan unit analisis berbeda.

\section{DAFTAR PUSTAKA}

Ambar Teguh Sulistiyani dan Rosidah, 2009. Manajemen Sumber Daya Manusia. Yogyakarta: Graha Ilmu.

Dessler, Gerry, 2007. Perilaku Organisasi Cetakan Ke V, Jakarta: Gramedia Pustaka.

Dwiyanto, Agus, 2012. Manajemen Pelayanan Publik Yogyakarta: Gadjah Mada University Press.

Eisenberger, R., Huntington, R., Hutchison, S., \&Sowa, D. (1986). Perceived Organizational Support. Journal of Applied Psychology,500-507.

Eisenberger, Stinglhamber, Vandenberghe, Sucharski \& Rhoades. (2002). Perceived

Supervisor Support: Contributions to Perceived Organizational Support and Employee Retention. Journal of Applied Psychology. Vol. 87, No.3, 565-573.

Hair, Joseph F. Jr, Ralph E. Andersen, Ronald L. Tatham, William C. Block. (2006). Multivariate Data Analysis, 8th Edition, New Jersey: Prentice Hall. Inc.

Istijanto, 2005. Aplikasi Praktis Riset Pemasaran, Jakarta: PT Gramedia. 
Komalasari Tri Puput. 2012. Pengaruh Public Service Motivation dan Organizational Citizenship Behavior Terhadap Kinerja Organisasi Pemerintahan. Jurnal Akuntansi Nomor 4 Volume 2. Universitas Erlangga, Surabaya.

Komalasari, Tri Puput, 2012. Pengaruh Public Service Motivation dan Organizational Citizenship Behavior Terhadap Kinerja Organisasi Pemerintahan. Jurnal Akuntansi Nomor 4 Volume 2. Universitas Erlangga, Surabaya.

Mahmudi, 2011.Akuntansi Sektor Publik, Yogyakarta: UII Press

Mahsun, Mohamad, 2012. Pengukuran Kinerja Sektor Publik, Yogyakarta: BPFE UGM.

Nordiawan, Dedi, 2009. Akuntansi Pemerintahan Edisi kesatu, Jakarta: Salemba Empat

Organ, D.W., Podsakof, M.P., MacKenzie, B.S. 2006. Organizational Citizenship Behavior. USA: Sage Publications, Inc.

PadSakoff, 2000.Organizational Citizenship Behaviour Pada Karyawan. Edisi Indonesia, Sosial Ekonomi. McGraw-Hill, Irwin.

Pasolong Harbani, 2010.Teori Administrasi Publik, Bandung: Alfabeta.

Perry and Annie Hondeghem, James L, 2008. Motivation in Public Management, New York: Oxford University Press Inc.

Perry, James L. "Measuring Public Services Motivation: An Assessment of Construct Realibility and Validity". Journal of Public Administration Research and Theory (JPART). Volume 6 No.1.

Perry, James, L. and Lois Recascino Wise. 1990. "The Motivational Bases of Public Service" Public Administration Review 50 (May/June).

Perry, James, L. And Lois Recascino Wisee. 1990. “The Motivational Bases of Public Service”. Public Administration Review 50 (May/June): 367-373.

Rhoades \& Eisenberger, 2002. Perceived Organizational Support: A review of The Literature, Journal of Applied Psychology. Vol. 87, No. 4, 698-714.

Robbins Steven P dan Timothy, 2008. Perilaku Organisasi. Edisi Terjemahan, Jakarta: Erlangga.

Sekaran, Uma. 2007. Metode Penelitian untuk Bisnis Edisi 4, Buku 2, Jakarta: Salemba Empat.

Sugiyono, 2004. Metode Penelitian Bisnis. Bandung: Alfabeta, CV.

Sugiyono, 2013. Metode Penelitian Kuantitatif Kualitatif dan R \& D, Bandung: Alfabeta.

Supomo, Bambang dan Nur Indriantoro, 2002. Metodologi Penelitian Bisnis, Cetakan Kedua, Yogyakara: Penerbit BFEE UGM.

Wijanto, Setyo Hari, 2008. Structural Equation Modeling dengan LISREL 8.8, Yogyakarta: Graha Ilmu. 